\title{
INDUKSI PERTUMBUHAN BENIH TANAMAN CABAI (Capsicum frutescens L.) DENGAN PUPUK HAYATI
}

\author{
Jefri Nur Hidayat ${ }^{1}$, Dyah Ayu Fajarianingtyas ${ }^{2}$ \\ FKIP, Universitas Wiraraja ${ }^{1,2}$ \\ jefryayak@gmail.com ${ }^{1}$, tanzilkurnain@gmail.com ${ }^{2}$
}

\begin{abstract}
ABSTRAK
Penelitian ini dilakukan untuk mengetahui pertumbuhan benih tanaman cabai yang diinduksi menggunakan pupuk hayati dengan kode RzMO. Perlakuan pemberian terdiri dari konsentrasi 0 (Pz0), $10 \mathrm{~mL}(P z 1), 20 \mathrm{~mL}(P z 2), 30 \mathrm{~mL}(P z 3)$. Pertumbuhan yang diukur adalah kemampuan tumbuh biji cabai pada minggu ke 1 dan ke 2. Hasil penelitian menunjukkan bahwa kemampuan tumbuh biji minggu ke 1 yaitu PzO sebesar 20\%, Pz1 sebesar 13\%, Pz2 sebesar 47\%, dan Pz3 30 sebesar 60\%. Sedangkan kemampuan tumbuh biji minggu ke 2 yaitu PzO sebesar 47\%, Pz1 sebesar 47\%, Pz2 sebesar $87 \%$, dan Pz3 sebesar $80 \%$.
\end{abstract}

Kata kunci : Capsicum frutescens $L$, pupuk hayati, pertumbuhan benih

\section{PENDAHULUAN}

Sayuran merupakan sumber nutrisi penting untuk menjaga kesehatan, salah satunya yaitu cabai (Capsicum frutescens L). Buah cabai memiliki vitamins yang tinggi seperti vitamin $\mathrm{C}, \mathrm{E}$ dan provitamin A. Kandungan vitamin $\mathrm{C}$ dapat berfungsi sebagai antioksidan. Selain itu, cabai juga mengandung capsaicin yang digunakan sebagai bahan baku industri farmasi pada pembuatan cream untuk mengurangi rasa sakit pada otot (Bosland and Votava, 2012). Karena banyak manfaatnya, ketersediaan buah cabai dipasaran semakin sedikit jumlahnya. Produksi cabai rawit segar tahun 2012 sebesar 7.120 ton. Sedangkan pada tahun 2013 terjadi penurunan produksi sebesar 313 ton $(4,21 \%)$. Penurunan ini disebabkan penurunan produktivitas sebesar 0,17 ton per hektar (-3,47 persen) (BPS, 2013). Hal ini menyebabkan harga buah cabai mencapai Rp 100.000/kg bahkan lebih dibeberapa daerah. Untuk memenuhi ketersediaan buah cabai dipasaran, petani dapat meningkatkan jumlah tanaman dan mempercepat pertumbuhan cabai berbagai cara, salah satunya dengan penggunaan pupuk, yaitu pupuk kimia maupun pupuk hayati.

Pupuk merupakan senyawa yang dapat meningkatkan pertumbuhan tanaman, diberikan melalui tanah dan ambil oleh akar tanaman untuk diangkut ke daun atau organ lainnya (Elsworth and Paley, 2009). Pupuk hayati (biofertilizer/bio-inoculant) merupakan zat yang didalamnya mengandung mikroorganisme hidup yang dapat hidup dan berkoloni di rizosfir tanaman serta meningkatkan pertumbuhan dengan meningkatkan pasokan atau ketersediaan unsur hara dan atau menghasilkan hormon yang menstimulus pertumbuhan tanaman, ketika diterapkan untuk benih, permukaan tanaman, atau tanah (Sun Suh, Jang et al., 2006). Mikroorganisme dalam pupuk hayati diantaranya mikroba penambat nitrogen, pelarut fosfat, potasium (Rao, 1994), mikroba perombak bahan organic dan penghasil fitohormon (Boonkerd, 2006). Mikroba ini akan meningkatkan ketersediaan unsur nutrisi makro dan fitohormon yang diperlukan oleh selama pertumbuhan tanaman (Wilkinson, 2000). Pupuk hayati yang tersedia di pasaran bermacam macam jenisnya misalnya Petro Biofer, Bio K2, 
EM4 dan Welirang. Pupuk hayati dapat digunakan untuk meningkatkan laju pertumbuhan dan hasil panen cabai.

Berdasarkan latar belakang tersebut, penelitian ini dilakukan untuk mengetahui pertumbuhan benih cabai yang diinduksi menggunakan pupuk hayati dengan kode RzMO.

\section{METODE PENELITIAN}

\section{Waktu dan tempat}

Penelitian dilakukan di

Laboratorium Biologi dan diladang, Program Studi Pendidikan IPA, Fakultas Keguruan dan Ilmu Pendidikan.

\section{Alat dan Bahan}

Alat yang digunakan pipet volume, Erlenmeyer glass, Beaker glass, kuvet, autoclave, jerigen, cangkul, tabung ukur, bak perendam, polybag dan timbangan. Sedangkan bahan yang digunakan yaitu benih cabai (Capsicum frutescens L) dan pupuk hayati RzMO.

\section{Prosedur Kerja}

Pengukuran kekeruhan (densitas)

Mengukur pupuk hayati RzMO pada OD600 = 1, Apabila nilai pada panjang gelombang $600<1$ maka menambahkan RzMO.

Penanaman cabai (Capsicum frutescens $\mathrm{L}$ )

a. Penanaman dan perlakuan

Benih tanaman cabai direndam selama semalam. Kemudian membuat lubang dengan kedalaman $1 \mathrm{~cm}$ dan meletakkan benih. Melakukan pemberian konsentrasi perlakuan, yaitu $\mathrm{Pz0}$ (tanpa RzMO), Pz1 (10 mL RzMO per tanaman), Pz2 (20 mL RzMO per tanaman) dan Pz3 (30 mL RzMO per tanaman). Kemudian menutup benih dengan tanah dan menyiramnya dengan air hingga tanah menjadi lembab. Pemberian pupuk hayati dilakukan setiap 3 hari.

\section{b. Pemeliharaan tanaman}

Melakukan penyiraman secukupnya setelah benih ditanam, setiap pagi hari dan membersihkan gulma.

\section{Pengukuran pertumbuhan}

Pengukuran kemampuan pertumbuhan benih tanaman cabai dilakukan setiap minggu. Persentase kemampuan tumbuh menggunakan rumus:

$$
\%=\frac{\text { jumlah tanaman yang tumbuh }}{\text { total tanaman }}
$$

\section{Analisi data}

Analisis data kemampuan pertumbuhan benih tanaman cabai (Capsicum frutescens L) menggunakan analisis deskripsi.

\section{HASIL DAN PEMBAHASAN}

Hasil menunjukkan bahwa terjadi perbedaan kemampuan tumbuh benih dari tanaman cabai (Capsicum frutescens L), pada minggu ke 1: Pz0 yang dapat tumbuh sebanyak 3 tanaman (20\%), Pz1 sebanyak 2 tanaman (13\%), Pz2 sebanyak 7 tanaman (47\%), dan Pz3 sebanyak 9 tanaman $(60 \%)$. Pertumbuhan pada minggu ke 2: perlakuan $\mathrm{Pz0}$ sebanyak 7 tanaman (47\%), Pz1 sebanyak 7 tanaman (47\%), Pz2 sebanyak 13 tanaman (87\%), dan Pz3 sebanyak 12 tanaman (80\%). (Gambar 1)

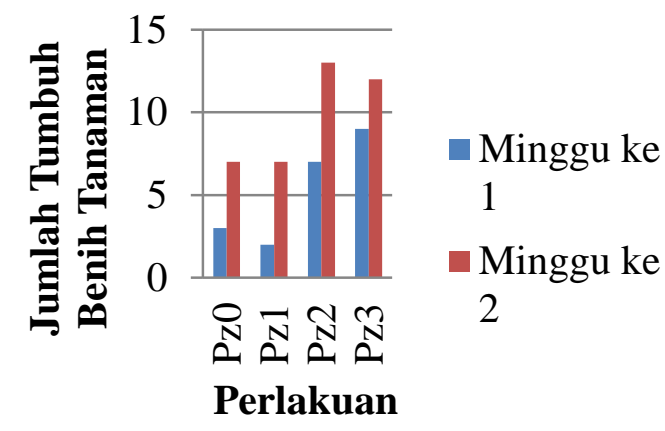

Gambar 1. Kemampuan Tumbuh Tanaman Cabai (Capsicum frutescens L) Pada Minggu Ke 1 Dan Minggu Ke 2.

Pertumbuhan tanaman dapat diartikan sebagai peningkatan volume sel yang bersifat irreversible (Taiz and Zeiger, 2002). Pertumbuhan merupakan salah satu parameter yang dapat diamati untuk mengetahui pengaruh berbagai faktor biotik dan abiotik dilingkungan. Pertumbuhan pada tanaman dapat diinduksi oleh pupuk seperti pupuk 
hayati. Pupuk hayati atau biofertilizer merupakan substansi yang berisi mikroorganisme hidup yang dapat mengkolonisasi rhizosfir atau bagian dalam akar tanaman dan memacu pertumbuhan (Sun Suh, Jang et al., 2006).

Berdasarkan hasil pengamatan, pemberian pupuk hayati dapat meningkatkan kemampuan tumbuh benih tanaman cabai (Capsicum frutescens L) pada minggu ke 1 dan minggu ke 2 . Hal ini diduga disebabkan oleh kemampuan mikroorganisme pupuk hayati dalam penyediaan unsur hara makro yang diperlukan tanaman dan menghasilkan zat pengatur tumbuh dalam lingkungan akar (White and Hammond, 2008).

Selain itu, mikroorganisme juga dapat mempengaruhi $\mathrm{pH}$ di rizosfer sehingga sangat berpengaruh terhadap penyerapan nutrisi pada akar serta meningkatkan transport unsur hara. Whitelaw, 2000 dan Taiz and Zeiger, 2002 menyatakan bahwa mikroorganisme dalam pupuk hayati dapat melepaskan asam organik yang berupa anion atau proton sehingga mineral yang terikat pada agregat tanah terlepas dan terjadi perubahan $\mathrm{pH}$. Ketika $\mathrm{pH}$ berada pada kondisi 5.5 sampai 6.5, maka penyerapan nutrisi dan unsur hara makro dapat berlangsung optimal dan terjadi pada semua permukaan akar (Clarkson dalam Taiz and Zeiger, 2002).

\section{KESIMPULAN}

Hasil penelitian menunjukkan bahwa kemampuan tumbuh biji minggu ke 1 yaitu ph0 sebesar 20\%, ph1 sebesar 13\%, ph2 sebesar 47\%, dan ph2 30 sebesar $60 \%$. Sedangkan kemampuan tumbuh biji minggu ke 2 yaitu ph0 sebesar 47\%, ph1 sebesar $47 \%$, ph2 sebesar $87 \%$, dan ph3 sebesar $80 \%$.

\section{REFERENSI}

Asad, S. A., Bano, A., Farooq, M., Aslam, M., and Afzal, A. 2008. Comparative Study of The Effects of Biofertilizers on Nodulation and Yield Characteristics of Mung Bean (Phaseolus vulgaris L.). International
Journal of Agriculture and Biology. Vol. 6, No. 5. Pakistan.

Boonkerd, N. 2006. Biofertilizer Development. Article. Thailand: Institute of Agricultural Technology, Suranaree University of Technology.

Bosland, Paul W and Eric J. Votava. 2012. Peppers : Vegetable and Spice Capsicums. 2Ed. UK: CABI.

BPS. 2013. Produksi Cabai Besar, Cabai Rawit, dan Bawang Merah Tahun 2013. Berita Resmi Statistik

Elsworth, Langdon R. and Walter O. Paley. 2009. Fertilizers : Properties, Applications and Effects. New York: Nova Science Publishers, Inc.

Rao, S. 1994. Mikroorganisme Tanah dan Pertumbuhan Tanaman. Edisi Kedua. Jakarta: Universitas Indonesia.

Sun Suh, Jang., Pan Jiarong., and Pham Van Toan. 2006. Forum for Nuclear Cooperation in Asia: Biofertilizer Manual. Japan: Japan Atomic Industrial Forum (JAIF).

Taiz, L., and Zeiger, E. 2002. Plant Physiology. 3rd Edition. Sunderland: Sinauer Associates.

Whitelaw, M. A. 2000. Growth Promotion Of Plants Inoculated With PhosphateSolubilizing Fungi. Advances in Agronomy, Volume 69. Boston: Academic Press.

White, P. J., and Hammond, J. P. 2008. Plant Ecophysiology: The Ecophysiology of Plant-Phosphorus Interactions. Vol 7. UK: Springer Science.

Wilkinson, R. E. 2000. PlantEnvironment Interactions. 2nd Edition. New York: Marcel Dekker Inc. 